such as the common extensor origin at the elbow or in the contents of the carpal tunnel.

The authors would like to thank Dr B B Seedhom for his invaluable help in checking the accuracy of the radiographic measurements, Mr H B Bentley for carrying out the radiography, Mrs R Hopkins for her help with the analysis of the results, and Mrs J Battersby for typing the manuscript.

This paper forms part of an MD thesis (CFML) to be submitted to the University of London.

\author{
References \\ ${ }^{1}$ Phalen, G S, fournal of Bone and foint Surgery, 1966, 48A, 211 \\ 2 Yamaguchi, D M, et al, Minnesota Medicine, 1965, 48, 22. \\ 3 Mangini, U, Bulletin of the Hospital for Foint Diseases, 1961, 22, 56. \\ 4 Lipscomb, P R, Clinical orthopaedics, 1959, 13, 164. \\ 5 Nissen, K I, fournal of Bone and foint Surgery, 1963, 45B, 620 \\ 6 Nissen, K I, personal communication, 1975
}

' Hombal, J W R, and Owen, R, Hand, 1970, 2, 192.

${ }^{8}$ Conklin, J E, and White, W L, Surgical Clinics of North America, 1960, 40, 431 .

${ }^{9}$ Dick, T B S, and Zadik, F R, British Medical fournal, 1958, 2, 288.

10 Kremer, H, et al, Lancet, 1953, 2, 590.

11 Garland, H, et al, British Medical fournal, 1957, 1, 730.

12 Kummel, B M, and Zazanis, G A, Clinical Orthopaedics, 1973, 92, 227.

13 Russell, W R, Proceedings of the Royal Society of Medicine, 1955, 49, 197.

14 Crymble, B, British Medical fournal, 1968, 3, 470.

15 Semple, J C, and Cargill, A O, Lancet, 1969, 1, 918.

16 Upton, A R M, and McComas, A J, Lancet, 1973, 2, 359.

17 Kemble, F, and Peiris, O A, Electromyography, 1967, 7, 127.

18 Council for International Organisations of Medical Sciences, Epidemiology of Chronic Rheumatism, vol 2, Atlas of Standard Radiographs of Arthritis. Oxford, Blackwell, 1963.

19 Pallis, C, et al, Brain, 1954, 77, 274.

20 Burrows, E H, Clinical Radiology, 1963, 14, 77.

21 Nurick, S, Brain, 1972, 95, 87.

22 Wilkinson, N, in Cervical Spondylosis: Its Early Diagnosis and Treatment, ed M Wilkinson, p 44. London, Heinemann, 1970.

23 Silberstein, C E, Clinical Orthopaedics, 1965, 40, 184.

24 Storey, G O, in Cervical Spondylosis: Its Early Diagnosis and Treatment, ed M Wilkinson, p 147. London, Heinemann, 1970.

\title{
Transplantation of tumour with a kidney graft
}

\author{
A D BARNES, M FOX
}

British Medical fournal, 1976, 1, 1442-1444

\section{Summary}

A cerebral glioma discovered by angiography and brain biopsy in a kidney donor was subsequently suspected of being a secondary tumour. By this time a biopsy of one of the transplanted kidneys had shown a clump of malignant cells in a glomerulus. Because of the psychological state of this recipient the transplant was not removed, but the recipient of the second kidney was immediately told of the danger of tumour cell transfer, and underwent nephrectomy. The patient remained well on haemodialysis; multiple sectioning of the kidney showed no signs of tumour. The transplant in the first recipient functioned well until his death, six months after operation. At necropsy undifferentiated tumour was found in the pleura, liver, pelvic peritoneum, and transplanted kidney.

All cadaver donors should undergo full laparotomy after removal of the kidneys, particularly those with a high risk of cancer, and a full necropsy should also be performed shortly afterwards to exclude tumour and other unsuspected diseases. Then it is not too late to remove a transplanted kidney should a tumour be found.

\section{Introduction}

The possibility of transplanting tumour tissue with a kidney graft is a danger that must always be borne in mind. The tumour may be of renal origin ${ }^{12}$ or it may arise from structures outside the kidney. ${ }^{3} 4$ It is difficult "successfully" to transplant malignant tissue into a normal person, but after immunosuppression

Renal Transplant Unit, Queen Elizabeth Hospital, Birmingham A D BARNES, CHM, FRCS, consultant surgeon and director

host resistance is lowered, with subsequent survival, multiplication, and dissemination of tumour cells. Transplantation of organs from donors with malignant disease should thus not be performed even if the tumour is apparently localised (apart from primary brain tumours), as one cannot be certain whether or not microscopic spread has occurred.

The difficulties encountered in prompt detection of a tumour in the cadaver donor, the advice given to the recipients after transplantation of kidneys at risk, and subsequent management are illustrated in the following report of a donor and two recipients.

\section{Donor}

The donor was a 45-year-old male chronic schizophrenic who was transferred to a general hospital because of a fit and the rapid onset of deep unconsciousness. He developed respiratory depression and required ventilation to enable a diagnosis to be made. A cerebral angiogram showed a cerebral tumour, which a brain biopsy showed to be a glioma. On these grounds the patient was deemed to be suitable as a kidney donor. After certification of death both kidneys were removed for transplantation with a warm ischaemic time of 13 minutes. At nephrectomy no intra-abdominal disease was found. A chest $x$-ray picture was normal. A full necropsy was, however, not performed.

After the renal transplants had been performed the radiologist queried the angiographic appearances as being of a secondary rather than a primary brain tumour and the pathologist gave a cautious interpretation of the brain biopsy in view of the necrosis present.

Two patients received kidneys through the National Organ Sharing Scheme on the basis of HLA match. The tissue typing is shown in the table. Preservation was with a cold flush with dextran 40 in dextrose and ice storage. Anatomically the kidneys were normal and no features of pathological significance were seen on the cortical surface or in the hilum.

Tissue typing of donor and two recipients

\begin{tabular}{|c|c|c|c|c|c|c|c|c|}
\hline \multirow[b]{2}{*}{$\begin{array}{l}\text { Donor } \\
\text { Recipient } 1 \\
\text { Recipient } 2\end{array}$} & \multirow[b]{2}{*}{$\begin{array}{l}\cdots \\
\cdots\end{array}$} & \multirow[b]{2}{*}{$\begin{array}{l}\cdots \\
\cdots\end{array}$} & \multirow[b]{2}{*}{$\begin{array}{l}\text { A } \\
\text { A } \\
\text { A }\end{array}$} & \multirow[b]{2}{*}{$\begin{array}{l}\mathrm{Rh}+ \\
\mathrm{Rh}+ \\
\mathrm{Rh}+\end{array}$} & \multicolumn{2}{|c|}{ HLA-A } & \multicolumn{2}{|c|}{ HLA-B } \\
\hline & & & & & $\begin{array}{l}2 \\
2 \\
2\end{array}$ & $\begin{array}{c}11 \\
3 \\
\text { W } 29\end{array}$ & $\begin{array}{l}\text { W } 5 \\
\text { W } 5 \\
\text { W } 5\end{array}$ & $\begin{array}{ll}W & 10 \\
W & 10 \\
W & 19\end{array}$ \\
\hline
\end{tabular}




\section{Recipient 1}

A 56-year-old man developed polyarthritis, ulcerative skin lesions, and a slowly progressive renal failure; he had low serum complement concentration and was positive for antinuclear factor. The renal biopsy appearances were compatible with systemic lupus erythrematosus, but Schönlein-Henoch disease was an alternative diagnosis. Despite medical treatment, during which he also developed gastrointestinal haemorrhage and angina, his renal function deteriorated and by the age of 60 he needed haemodialysis. He was trained and installed on home dialysis when his physical condition was good, and there were no technical problems with dialysis. By the time he was 61 , however he was psychologically unable to tolerate dialysis any longer. He had written to transplant units in many parts of the world requesting a graft before being referred to his local unit. He appeared young for his age and was therefore accepted for a cadaveric graft on the strict undertaking that he would not return to dialysis should the graft fail. An offer of a live donor transplant from his daughter was declined.

The left kidney was transplanted in the right iliac fossa by our usual technique. A routine cortical biopsy specimen was taken at the end of the operation, about 20 minutes after re-establishing the circulation. There were two weeks of oliguria, after which normal renal function rapidly developed (blood urea $7 \cdot 5-8.5 \mathrm{mmol} / 1(45-51 \mathrm{mg} / 100 \mathrm{ml}$ ), creatinine $100-140 \mu \mathrm{mol} / 1 \quad(1 \cdot 13-1.58 \mathrm{mg} / 100 \mathrm{ml}))$. This excellent function persisted until death. No rejection episodes were diagnosed or treated. By the end of three months prednisone had been reduced from an initial dose of $75 \mathrm{mg} /$ day to $17.5 \mathrm{mg} /$ day. The dose of azathioprine was never above $100 \mathrm{mg}$ /day.

The anxiety during this man's early postoperative course was caused by the finding in the otherwise histologically normal biopsy specimen of one glomerulus containing a small clump of malignant cells within the glomerular capillaries. This was interpreted as a tumour embolism from an undifferentiated carcinoma. On review the cytological features of this embolus were not the same as those in the brain biopsy specimen from the donor. This information was communicated to the surgical team looking after the second recipient (see below), who removed their transplant immediately and subjected the graft to multiple sectioning. No sign of tumour was found.

We were in a dilemma with this patient. The embolism may have been from the donor or possibly from the recipient who, although well, was a smoker. The absence of tumour in the removed graft and the psychosocial aspects of the first recipient gave us no option but to leave the graft in situ.

The patient remained well for four and a half months. He developed a pain in his left loin for which no cause could be found, and two weeks later a large left pleural effusion was diagnosed. Over the next three weeks he rapidly deteriorated, with bilateral pleural effusions. Bronchoscopy and examination of the pleural fluid showed nothing abnormal. A pleural biopsy, however, showed an anaplastic pleomorphic tumour, most probably of bronchial origin. There was no response to the addition of bleomycin, cyclophosphamide, and mustine to his treatment. He would not consider stopping prednisone or azathioprine.

Necropsy showed a well-nourished man, young for his age. The left lung was firmly adherent to the chest wall by dense white tumour. The right lung had nodules of tumour on its surface. There was no sign of tumour in the bronchial tree, even in the smallest branches. The tumour in the pleura did not infiltrate the lung, which was the site of a terminal bronchopneumonia. There were tumour nodules on the pericardium and in the liver. The peritoneum of the pelvis was studded with tumour nodules, especially on the side of the transplant. The transplant itself weighed $250 \mathrm{~g}$. In the perirenal donor tissues and on the cortical surface were multiple nodules up to $2 \mathrm{~cm}$ in diameter. The cut surface of the kidney showed the nodules to be in both the cortex and medulla. There were two small benign colonic polyps and a benign adenoma of the thyroid gland. Histologically tumour tissue from the pleura, liver, pelvic peritoneum, and transplanted kidney was pleomorphic and undifferentiated. There were many bizarre and multinucleated cells with eosinophilic cytoplasm, but special stains did not show any identifying features. There were no signs of rejection in the transplant, and the patient's own kidneys had no features of diagnostic help.

\section{Recipient 2}

A 38-year-old married man with three young children suffering from terminal renal failure from polycystic kidney disease had been maintained on haemodialysis for 15 months, 10 of them with a machine in his own home. His general condition was good and he was working full-time as a fitter.

The right kidney was placed in the left iliac fossa by our usual technique. It became pink and turgid within several seconds of removing the vascular clamps after a total ischaemic period of 5 hours 54 minutes. Mannitol and frusemide were given intravenously when the clamps were removed, and urine secretion started after 12 minutes. Prednisolone, azathioprine, and goat antilymphocytic globulin were used as immunosuppressive agents.

The immediate postoperative period was satisfactory apart from degree of partial tubular shutdown; this was clearing by the 5 th day, when urine output had reached $1200 \mathrm{ml} / 24$ hours. At this stage it became known that peroperative biopsy of the other kidney had shown a small focus of malignant tumour cells and that the clinical diagnosis of glioma in the donor had been revised to that of a metastasis from an unknown primary tumour.

The problem was openly discussed with the patient and his wife the same day. In view of the real danger of tumour cell transfer and subsequent uncontrollable metastatic spread, nephrectomy was advised and accepted. The kidney was removed the same day and the patient remained well 12 months later, awaiting a second transplant. Histological examination of multiple sections of the kidney graft showed no evidence of tumour.

\section{Discussion}

Transplantation of a kidney from a donor who has cancer will not transfer the tumour to the recipient unless malignant cells are present within the kidney. Serial-section histological studies are not available to determine the incidence of metastatic spread to the kidney from various cancers either early or late. Necropsies have shown macroscopic metastases to be present in the kidney in $8 \%$ of all cases of malignant tumours coming to necropsy, with the highest incidence with breast, lung, and gastrointestinal tract tumours. ${ }^{5}$ These figures are likely to underestimate grossly the true (microscopic) incidence, while they give the results in advanced malignancy and are not applicable to a transplant donor.

In view of the known high incidence of tumour transfer into immunosuppressed recipients with kidney grafts, ${ }^{6}$ the advice that had to be given to the second patient was never in doubt, particularly when tumour had been found in the contralateral kidney. The patient was young and in good health and the risks of nephrectomy and a further period on haemodialysis and retransplantation were not considered to be anywhere near as high as those of the very likely transfer and subsequent proliferation of tumour. Widespread microscopic dissemination of the tumour must have occurred in the donor in view of the renal metastasis. The absence of demonstrable neoplasm in the kidney after removal did not subsequently change in our view that the organ should have been removed. Serial sections were not cut and a small collection of tumour cells may have been missed. The final outcome in the first recipient made us very glad that the kidney had been taken out promptly and immunosuppressive treatment stopped. On the other hand, the particular circumstances of the first case allowed us to document the growth of metastases from a few cells to a widely disseminated cancer with nodules of more than $2 \mathrm{~cm}$ in diameter in six months. The indications for not removing the transplant in recipient 1 were as strong as those for nephrectomy in the second case. Both physically and psychologically the first patient could not undergo nephrectomy and return to dialysis. He had four months of normal life, for which he and his relatives remained intensely grateful.

Full laparotomy is recommended in all cadaver donors after removal of kidneys for transplantation, particularly in those at high risk of cancer because of their age. If a lesion indicative of neoplasm is found a frozen section can save unnecessary effort and the risk of tumour dissemination in an immunosuppressed recipient. ${ }^{1}$ A full necropsy within a day or two of organ removal should also be performed in all transplant donors to exclude tumour or other unsuspected disease such as tuberculosis. Even 
then it is probably not too late to stop immunosuppression and remove the kidney without the risk of tumour transfer.

\section{References}

${ }^{1}$ Fox, M, Transplantation, 1973, 15, 523.
${ }^{2}$ Baird, R N, White, H J O, and Tribe, C R, British Medical fournal, 1975, 2, 371 .

3 Wilson, R E, et al, New England fournal of Medicine, 1968, 278, 479.

${ }^{4}$ Zukoski, C F, et al, Transplantation, 1970, 9, 71.

5 Willis, R A, Pathology of Tumours, 4th edn, p 175. London, Butterworth, 1967.

6 Penn, I, Transplantation Proceedings, 1975, 7, 553.

\section{SHORT REPORTS}

\section{Pulmonary fibrosis associated with hypersensitivity to gold salts}

The pulmonary fibrosis associated with rheumatoid arthritis (RA) is usually thought to be a part of the systemic disease. In some cases an adverse reaction to a drug may be an equally valid explanation. We report a patient with rheumatoid disease in whom gold seems to have been responsible for the development of pulmonary fibrosis.

\section{Case report}

A 54-year-old nurse presented with pulmonary fibrosis in 1973. Rheumatoid arthritis had been diagnosed in 1962 and treated with analgesics until gold was started in December 1972. At that time she had no respiratory symptoms and her chest $x$-ray picture was normal.

In April 1973 after she had received $655 \mathrm{mg}$ of sodium aurothiomalate she had a dry cough and was breathless on minimal exertion. The chest $x$-ray film showed diffuse bilateral shadowing. The gold was stopped. The only other drugs taken over this period were indomethacin and ferrous sulphate (Feospan), both of which she had taken for some years.

A lung biopsy in July 1973 showed fibrosing alveolitis. She refused steroid treatment. Her breathlessness steadily improved and in July 1974 she could climb three flights of stairs. At this time gold was restarted for an exacerbation of her arthritis. In October 1974 she again had a dry cough and was breathles and by March 1975 she could walk only 9 metres (10 yards) on the flat. Gold was stopped and prednisone $15 \mathrm{mg}$ a day started. Over the next nine month her symptoms resolved, lung function improved, and the chest radiograph cleared slightly.

On examination in April 1975 there was no clubbing, and crackles were heard over both lung fields. The pulse was regular $(80 / \mathrm{min})$, blood pressure was $130 / 80 \mathrm{~mm} \mathrm{Hg}$, and there was no evidence of cardiac failure. There were the changes of RA affecting the knees, wrists, and hands. The remainder of the physical examination was negative.

Investigations while taking gold showed haemoglobin $11.0 \mathrm{~g} / \mathrm{dl}$, white cells $6.4 \times 10^{9} / 1\left(6400 / \mathrm{mm}^{3}\right)$, differential count normal, and no eosinophilia. Serum urea, electrolyte, and enzyme levels were repeatedly normal. The creatinine clearance was $106 \mathrm{ml} / \mathrm{min}$, and there was no significant proteinuria. The sheep cell agglutination test gave a positive result $(1 / 5120)$, and there were no LE cells. Lung function test results are shown in the table. Lymphocyte transformation to gold was tested by the method of Denman and Denman $^{1}$ using tritiated thymidine incorporation and was strongly positive. Lymphocyte transformation was negative in four normal subjects and also in four patients with rheumatoid disease taking gold without adverse reactions.

Lung function test results

\begin{tabular}{|c|c|c|c|c|c|}
\hline & Predicted & $\begin{array}{l}\text { June } \\
1973\end{array}$ & $\begin{array}{l}\text { April } \\
1975\end{array}$ & $\begin{array}{l}\text { Aug } \\
1975\end{array}$ & $\begin{array}{l}\text { Nov } \\
1975\end{array}$ \\
\hline $\begin{array}{l}\text { Forced expiratory volume in } 1 \text { s (1) } \\
\text { Vital capacity (1) }\end{array}$ & $\begin{array}{l}2 \cdot 25 \\
2 \cdot 70\end{array}$ & $\begin{array}{l}1 \cdot 30 \\
1 \cdot 50\end{array}$ & $\begin{array}{l}1 \cdot 15 \\
1 \cdot 25\end{array}$ & $\begin{array}{l}1.60 \\
1.70\end{array}$ & $\begin{array}{l}1.85 \\
1.95\end{array}$ \\
\hline $\begin{array}{l}\text { Carbon monoxide transfer factor } \\
\left(\mathrm{T}_{\mathrm{L}} \mathrm{CO}: \mathrm{mmol} / \mathrm{min} / \mathrm{kPa}\right)\end{array}$ & $7 \cdot 7$ & $2 \cdot 67$ & * & * & 3.04 \\
\hline
\end{tabular}

*Volumes too low to permit measurement of $\mathrm{T}_{\mathrm{L}} \mathrm{CO}$.

Conversion: SI to traditional units- $\mathrm{T}_{\mathrm{L}} \mathrm{CO}: 1 \mathrm{mmol} / \mathrm{min} / \mathrm{kPa} \approx 3.0 \mathrm{ml} / \mathrm{min} / \mathrm{mm} \mathrm{Hg}$.

\section{Discussion}

The appearance of pulmonary fibrosis during four months' gold treatment, the complete resolution of symptoms when gold was withdrawn, the recurrence of symptoms when gold was restarted, and resolution again on withdrawal strongly suggests that the gold was responsible for the fibrosis. A positive lymphocyte transformation response to gold has been shown to correlate well with adverse reactions to gold, ${ }^{1}$ although not with pulmonary fibrosis. Gold treatment has been reported to cause cough and dyspnoea ${ }^{2}$ and also pulmonary eosinophilia ${ }^{3}$ but not pulmonary fibrosis.

Reports on patients with rheumatoid lung often omit details of treatment. In one survey of 126 patients with seropositive rheumatoid disease nine had extensive pulmonary parenchymal disease. ${ }^{4}$ Six of these had received gold, and in five the gold was stopped because of a serious adverse reaction. Similarly in a study of lung function tests in patients with $\mathrm{RA}^{5} 47 \%$ of those with a reduced carbon monoxide transfer factor $\left(\mathrm{T}_{\mathrm{L}} \mathrm{CO}\right)$ had received gold compared with $25 \%$ of those with a normal $T_{L} C O$.

Gold may therefore be the cause of the pulmonary fibrosis in some patients with rheumatoid lung. Differences in prescribing habits may partly explain the reported differences in the incidence of rheumatoid lung.

We would like to thank $\mathrm{Dr} F \mathrm{H}$ Scadding for permission to report this case and Mrs Sue Pack for excellent technical help.

Requests for reprints should be addressed to $\mathrm{Dr} D \mathrm{D}$ Geddes, senior medical registrar, Westminster Hospital, London SW1P 2AP.

${ }^{1}$ Denman, E J, and Denman, A M, Annals of the Rheumatic Diseases, 1968, 27, 582.

2 Savilahti, M, Annales Medicinae Internae Fenniae, 1948, 37, 263.

3 Vaccarezza, R F, and Pavlovsky, A, fournal of the American Medical Association, 1946, 131, 1250.

${ }^{4}$ Sievers, K, et al, Acta Tuberculosea Scandinavica, 1964, 45, 21.

${ }^{5}$ Frank, S T, et al, Chest, 1973, 63, 27.

Middlesex Hospital and Medical School, London W1

D M GEDDES, MB, MRCP, medical registrar

JONATHAN BROSTOFF, MRCP, MRCPATH, senior lecturer, department of immunology

\section{Disintegration of cellulose dressings in open granulating wounds}

Doctors are responsible for the steady healing of their patients' granulating wounds but the wounds are dressed by nurses. The most common type of dressing is a gauze roll soaked in half-strength eusol and packed into the open wound once or twice daily. Gauze rolls were made of spun cotton until 1974, when the warp was changed to rayon or spun cellulose. When cellulose absorbs wound exudate it expands to a greater volume than cotton and causes discomfort in a shorter time.

\section{Patients, methods, and results}

Patients with a variety of granulating wounds are seen at a weekly clinic in the University Hospital of Wales. During the past three years about 100 patients a year have been treated. The dressing is removed. The wound is inspected carefully and washed with a cotton gauze square soaked in saline The skin is then shaved with a scalpel blade and the wound scrupulously cleaned once more to remove all hair.

Many patients have arrived with cellulose gauze dressings in their open granulating wounds. Six among the last 60 patients were found to have one 